\title{
Correction to: Radiation Dose Constraints for Organs at Risk: Modeling and Importance of Organ Delineation in Radiation Therapy
}

\section{G.A. Cefaro, D. Genovesi and C.A. Perez}

Correction to: G.A. Cefaro, D. Genoveis and C.A. Perez, Radiation Dose Constraints for Organs at Risk: Modeling and Importance of Organ Delineation in Radiation Therapy,

DOI:10.1007/978-88-470-5257-4_6

The word "normal standard dose" was incorrectly captured in the second paragraph of 3.2 Synopsis of Historical Perspective, p. 50 of this book. The word should read as "nominal standard dose". This has been corrected.

The updated online version of the original chapter can be found at https://doi.org/10.1007/978-88-470-5257-4_6 